\title{
The isotype repertoire of antibodies against novel UH-RA peptides in rheumatoid arthritis
}

Liesbeth M. De Winter ${ }^{1}$, Piet Geusens ${ }^{1,2,3}$, Jan Lenaerts ${ }^{4,5}$, Johan Vanhoof ${ }^{2}$, Piet Stinissen ${ }^{1}$ and Veerle Somers ${ }^{1 *}$

\begin{abstract}
Background: Recently, autoantibodies against novel UH-RA peptides (UH-RA.1 and UH-RA.21) were identified as candidate biomarkers for patients with rheumatoid arthritis (RA) who are seronegative for the current diagnostic markers rheumatoid factor and anticitrullinated protein antibodies. Previously, screening for anti-UH-RA autoantibodies was based on measuring the immunoglobulin (lg) $\mathrm{G}$ response. We aimed to investigate whether measurement of other isotypes could improve the performance of diagnostic testing. In addition, assigning the isotype profile might provide valuable information on effector functions of the antibodies.

Methods: The isotype profile of antibodies against UH-RA.1 and UH-RA.21 was studied. The IgG, IgM, and IgA classes, together with the 4 different IgG subclasses, were determined in 285 patients with RA, 88 rheumatic control subjects, and 90 healthy control subjects.

Results: Anti-UH-RA.1 antibodies were primarily of the lgM isotype and twice as prevalent as IgG (IgG3-dominated) and IgA. RA sensitivity when testing for anti-UH-RA.1 IgM was shown to be higher than when testing for the IgG isotype: $18 \%$ versus $9 \%$ sensitivity when RA specificity was set to $90 \%$. Within antibodies against UH-RA.21, IgG and IgA were more common than IgM. Different anti-UH-RA.21 IgG subclasses were found, with the highest prevalence found for IgG2. Combined testing for lgG and IgA slightly increased RA sensitivity of UH-RA.21-specific antibody testing to $27 \%$ compared with solely testing for lgG (23\%). Notably, a higher number of anti-UH-RA.21 antibody isotypes was related to increased levels of erythrocyte sedimentation rate. Finally, for both antibody responses, the full antibody isotype use was demonstrated in early and seronegative disease.
\end{abstract}

Conclusions: The isotype distribution of anti-UH-RA.1 and anti-UH-RA.21 antibodies was successfully outlined, and, for antibodies against UH-RA.1, we found that isotype-specific testing might have implications for diagnostic testing. The exact mechanisms by which the different antibody isotypes act still have to be unraveled.

Keywords: Rheumatoid arthritis, Autoantibodies, Biomarker, Antibody isotype, UH-RA peptides

\section{Background}

In the immunodiagnostics and pathogenicity of rheumatoid arthritis (RA), immunoglobulin (Ig) G is the most abundant antibody isotype in serum, and it is therefore most often used in clinical diagnostics. However, other Ig isotypes also have been proven to have utility. Testing for rheumatoid factor (RF), the first known antibody in $\mathrm{RA}$, relies on the presence of IgM rather than IgG or

\footnotetext{
* Correspondence: veerle.somers@uhasselt.be

${ }^{1}$ Biomedical Research Institute, Hasselt University, and School of Life Sciences, transnational University Limburg, Martelarenlaan 42, 3500 Hasselt, Belgium

Full list of author information is available at the end of the article
}

IgA, although all isotypes are present before diagnosis and have been shown to be associated with disease severity and radiological outcome [1-3]. Also, the isotype repertoire has been investigated in the other antibody system currently included in RA diagnostics: anticitrullinated protein antibodies (ACPA). In those studies, in addition to IgG, IgM and IgA isotypes were frequently encountered [4-7]. Patients with RA present with more, different ACPA isotypes than their family members, indicating a difference in isotype use between health and disease [5]. Years before RA onset, ACPA of the IgG and IgA classes are present and predict the development of 
RA [8]. The ACPA isotype repertoire expands toward RA development and in the early course of the disease $[4,5,9]$. Besides the presence of ACPA, a broader range of ACPA isotypes predicts a higher risk for radiographic damage [10]. Measurement of isotype-specific autoantibodies can thus provide valuable information related to RA diagnosis and prognosis. The autoantibody isotypes might give information on the source of the antigen recognition, the major effector function involved, and the pathogenicity of the antibodies.

Previously, the presence of autoantibodies against UHRA.1 and UH-RA.21-two novel peptides-was demonstrated in up to $23 \%$ of seronegative patients with RA and one-third of patients with early RA [11, 12]. Testing for the novel autoantibodies (combined as UHRA.PANEL2) was shown to reduce the serological gap by $9 \%$. On the one hand, antibodies against UH-RA.1 were associated with sustained disease-modifying antirheumatic drug (DMARD)-free remission. Anti-UHRA.21 antibodies, on the other hand, were linked with worse outcomes, as associations with the presence of erosions, inflammation, and higher tender and swollen joint counts were found.

The primary aim of this study was to explore isotype use within anti-UH-RA.1 and anti-UH-RA.21 antibodies. Patients with RA were cross-sectionally tested for antibodies of IgG and all of its subclasses (IgG1-IgG4), IgM, and IgA. The presence of multiple isotypes within the antibody response might have implications for diagnostic and prognostic use. Moreover, the results of this study might provide insight into the biological role of the circulating autoantibodies, as Ig isotypes differ in their localization and biological properties.

\section{Methods}

\section{Patient material}

This study was approved by the medical ethics committee of Hasselt University (UH), and informed consent was obtained from all participants. Plasma samples of 285 patients with RA, 88 rheumatic control subjects (RC), and 90 healthy controls (HC) were used. Samples from patients with RA and RC subjects were collected between 2003 and 2012 in three Belgian rheumatology clinics. The diagnosis of RA was based on fulfillment of the 1987 criteria for RA [13], and samples were collected within the first year of diagnosis for 36 patients (early patients). $\mathrm{HC}$ were included if they were at least 18 years old and healthy, without any underlying chronic illness. Samples were stored in the University Biobank Limburg.

\section{Clinical data}

The presence of erosions was registered as either present or absent. Additional clinical data retrieved from patients' records were erythrocyte sedimentation rate
(ESR), C-reactive protein, and the outcome of the Health Assessment Questionnaire together with disease activity measured using the Disease Activity Score in 28 joints, integrating measures of physical examination (tender and swollen joint counts), ESR, and patient selfassessment on a visual analogue scale. RF serology was evaluated in routine clinical laboratory testing with $\mathrm{RF}$ Latex reagent (upper limit of normal [ULN] $14 \mathrm{U} / \mathrm{ml}$; Beckman Coulter, Brea, CA, USA), the RF-II cobas c system (ULN $14 \mathrm{U} / \mathrm{ml}$; Roche, Vilvoorde, Belgium), or the SERODIA-RA test (Fujirebio Europe NV, Ghent, Belgium). ACPA testing was performed using the Phadia EliA cyclic citrullinated peptide (CCP) assay (CCP2; Thermo Scientific, Erembodegem, Belgium) or the QUANTA Lite CCP3 IgG enzyme-linked immunosorbent assay (ULN 19 units; INOVA Diagnostics Inc., San Diego, CA, USA).

\section{Peptide enzyme-linked immunosorbent assay}

Plasma samples were tested for antibodies of the IgG, IgM, and IgA isotypes. Patients with positive test results for IgG were further tested for subclasses 1-4. Samples were tested for the specific peptide (P) (UH-RA.1: GLQEFGTREKRQEITTE and UH-RA.21: PGGFRGE FMLGKPDPKPEGKGLGSPYIE) and an irrelevant control peptide (C) (WTKTPDGNFQLGGTEP) according to a protocol described previously [11], with the minor modification of use of polystyrene flat-bottom microplates (Greiner Bio-One, Wemmel, Belgium) [11]. Furthermore, binding of plasma antibodies was detected using rabbit antihuman IgG secondary antibody (1:2000; Dako, Heverlee, Belgium); monoclonal mouse antihuman IgG1, IgG2, IgG3, or IgG4 secondary antibody (1:1000; Life Technologies, Ghent, Belgium); rabbit antihuman IgA secondary antibody (1:500; Dako; or goat antihuman IgM secondary antibody (1:5000; SigmaAldrich, Diegem, Belgium). All antibodies were conjugated to HRP. All samples were tested in duplicate within each experiment, and experiments were performed independently at least twice. A positive sample was included in each experiment to control for interassay variability.

\section{Statistical analyses}

Antibody reactivity against UH-RA.1 and UH-RA.21 is expressed by the ratio of the optical density (OD) signal of specific peptide to the OD signal of control peptide. For each test, the cutoff value was set to $90 \%$ specificity based on reactivity in the $\mathrm{HC}$ group. Proportions were compared by using the $\chi^{2}$ or Fisher's exact test (expected count $<5$ ), while continuous data were compared between groups using the Mann-Whitney $U$ test (MWU) for two groups or the Kruskal-Wallis test for more than two groups. Spearman's $\rho$ correlations were applied to 
study associations between continuous data. For all statistical tests, a $p$ value $<0.05$ was considered statistically significant. Statistical analyses were performed using Prism version 5 (GraphPad software, La Jolla, CA, USA), IBM SPSS Statistics for Windows version 22.0 (IBM, Armonk, NY, USA), and JMP Pro version 11.2 (SAS Institute, Cary, NC, USA) software.

\section{Results}

\section{Isotype distribution of anti-UH-RA.1 and anti-UH-RA.21} antibodies

The contribution of individual Ig classes of the IgG, IgM, and IgA types to total reactivity of anti-UH-RA.1 and anti-UH-RA.21 antibodies was investigated in 285 patients with RA, $88 \mathrm{RC}$, and $90 \mathrm{HC}$. The characteristics of our study population are provided in Table 1 . Within the two antibody responses, the full isotype use was present.

\section{Anti-UH-RA.1 antibodies}

Antibodies against UH-RA.1 were found in 130 individuals (82 RA, $26 \mathrm{RC}$, and $22 \mathrm{HC}$ ). Within these antibodies, IgM was most common, found in almost twice as many anti-UH-RA.1 antibody-positive patients compared with IgG and IgA (IgM 76/130 [58 \%] versus IgG 44/130 [34 \%] and IgA 40/130 [31 \%]) (Fig. 1a). The distribution of the different isotypes was similar among patients with RA and RC (Fig. 1b). Twenty-nine IgGpositive individuals-of whom 19 were patients with RA, 6 were $\mathrm{RC}$, and 4 were $\mathrm{HC}$-were further subtyped for IgG1, IgG2, IgG3, and IgG4. This subtyping demonstrated that IgG reactivity was attributable mainly to the IgG3 subclass (Fig. 1a and c). IgG3 was present in 17 of 19 IgG-positive patients with RA and in all of the IgGpositive control subjects. IgG1 and IgG2 were RAspecific, but with a limited prevalence of 2 of 19 and 1 of 19, respectively (Fig. 1c). Anti-UH-RA.1 antibodies of the IgG4 subclass were not detected.

Up to 26 (20\%) of 130 of the anti-UH-RA.1 antibodypositive individuals harbored more than one antibody isotype (Table 2). When patients harbored two different antibody isotypes, mainly the combination of IgG with IgA $(11 / 22)$ or IgA with IgM $(9 / 22)$ was found, while the combination of IgG with IgM was less common $(2 / 22)$.
This pattern was also reflected by correlations between the levels of the different antibody isotypes: IgG levels were correlated with IgA levels (Spearman's $\rho=0.254$, $p<0.0001)$, and IgA levels were correlated with IgM levels $(\rho=0.269, p<0.0001)$. No correlation was found between IgG and IgM $(p=0.984)$. Finally, due to the dominant role of IgG3, only two patients with RA carried more than one IgG subclass.

\section{Anti-UH-RA.21 antibodies}

Antibodies against UH-RA.21 were found in 158 individuals (103 RA, $33 \mathrm{RC}$, and $22 \mathrm{HC}$ ). In contrast to the antibody system against UH-RA.1, IgM was less redundant within antibodies against UH-RA.21: IgG and IgA were both twice as prevalent (IgM 35/158 [22 \%] versus IgG 85/158 [54 \%] and IgA 86/158 [54\%]) (Fig. 1d). Although not significant, the presence of IgG was higher in patients with RA than in RC, in whom IgM and IgA appeared slightly more often (Fig. 1e). IgG subtyping was performed in 67 IgG-positive patients (51 RA, 10 $\mathrm{RC}$, and $6 \mathrm{HC}$ ). IgG2 was the most dominant isotype (30/51 [59 \%]), followed by IgG3 (11/51 [22 \%]) and IgG1 (4/51 [8 \%]) (Fig. 1d and f). The latter two were present only in the RA and RC groups, whereas only IgG2 was found in the HC group. Anti-UH-RA.21 IgG4 antibodies were detected in one patient with RA (Fig. 1f).

For anti-UH-RA.21 antibodies, 36 of 158 individuals carried two different antibody isotypes (27 RA, $6 \mathrm{RC}$, and $3 \mathrm{HC}$ ) (Table 2). Six individuals carried three different antibody isotypes (4 RA, $1 \mathrm{RC}$, and $1 \mathrm{HC}$ ) (Table 2). Co-occurrence of two isotypes was dominated by $\mathrm{IgG} /$ IgA (26/36), while IgA/IgM (7/36) and IgG/IgM (3/36) were less frequently observed. IgA levels correlated with both IgG levels $(\rho=0.236, p<0.0001)$ and IgM levels $(\rho=0.209, p<0.0001)$, while IgG and IgM levels were not correlated $(p=0.247)$. The correlation between IgA and IgG levels was present only in the RA group.

\section{Implications of antibody isotype profiling for rheumatoid arthritis diagnostics}

The diagnostic sensitivity of the anti-UH-RA.1 and antiUH-RA.21 antibodies previously reported was established using a detection antibody directed against IgG,

Table 1 Characteristics of patients and controls tested for $\lg G$, IgM, and IgA isotypes of antibodies against UH-RA.1 and UH-RA.21

\begin{tabular}{llllllll}
\hline Diagnosis & Number of subjects & Age, years & Female sex & Disease duration, years & RF-positive & ACPA-positive & RF/ACPA-positive \\
\hline RA & 285 & $60.1 \pm 12.1$ & $68 \%$ & $8.4 \pm 7.8$ & $56 \%$ & $48 \%$ & $63 \%$ \\
RC & 88 & $49.5 \pm 11.6$ & $42 \%$ & $10.2 \pm 7.9^{a}$ & NA & NA & NA \\
HC & 90 & $38.7 \pm 15.1$ & $63 \%$ & NA & NA & NA & NA \\
\hline
\end{tabular}

Abbreviations: $A C P A$ anticitrullinated protein antibodies, $H C$ healthy control subjects, NA not applicable or not available, $R A$ patients with rheumatoid arthritis, $R C$ rheumatic control subjects, $R F$ rheumatoid factor

Data are mean \pm SD unless otherwise indicated

a Unknown for 17 RC 
UH-RA.1

a

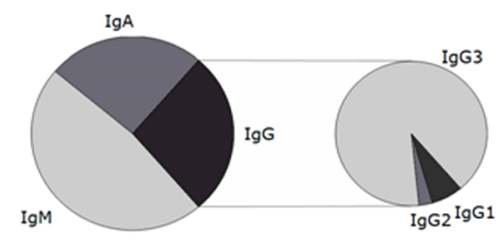

b

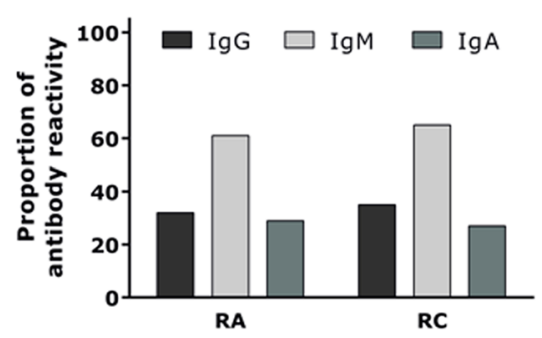

C

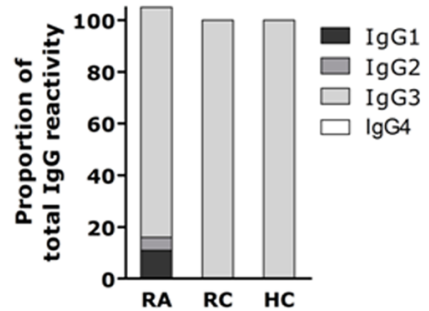

UH-RA. 21

d

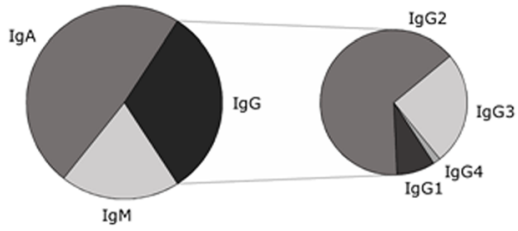

e

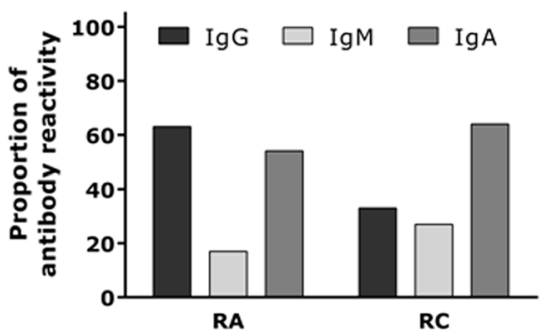

f

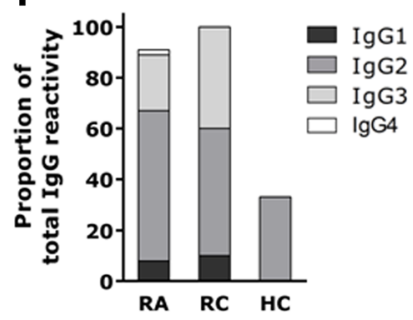

Fig. 1 Prevalence of the lgG, IgM, and lgA (sub)classes within anti-UH-RA.1 antibodies and anti-UH-RA.21 antibodies. a Anti-UH-RA.1 and d anti-UH-RA.21 antibodies of the lgG, IgM, and IgA isotypes. $\mathbf{b}$ and $\mathbf{e}$ With cutoffs based on HC reactivity and set to $90 \%$ RA specificity, the proportion of IgG, IgM, and IgA was similar in patients with RA and RC for antibodies against UH-RA.1 and UH-RA.21. c Subtyping of IgG-positive patients for lgG1-lgG4 pointed toward lgG3 as the dominant subclass within anti-UH-RA.1 antibodies in all patient and control groups. Anti-UH-RA.1-lgG1 and anti- UH-RA.1-lgG2 were RA-specific but less prevalent. No anti-UH-RA.1 antibodies of the lgG4 isotype were detected. $\mathbf{f}$ Regarding anti-UH-RA.21, IgG was represented mostly by $\lg \mathrm{G} 2$, followed by lgG3 and IgG1. The latter two were less prevalent but not found in HC. Anti-UH-RA.21 antibodies of the lgG4 isotype were detected in one patient with RA. Bars represent the proportion of the respective isotype to the total antibody reactivity. Sums of individual proportions within the same patient group can exceed $100 \%$ because patients can carry more than one (sub)class. HC healthy control subjects, Ig immunoglobulin, RA rheumatoid arthritis, $R C$ rheumatic control subjects

with only minimal cross-reactivity to other isotypes. However, since antibody reactivity is represented not only by IgG but also by IgM and IgA, we evaluated if isotypespecific testing could improve the diagnostic performance of anti-UH-RA.1 and anti-UH-RA.21 antibodies.
The levels of isotype-specific antibodies against UHRA.1 and UH-RA.21 are depicted in Fig. 2. Depending on the antibody isotype, anti-UH-RA.1 antibody levels were significantly higher in patients with RA than in RC (IgG, IgA) or HC (IgM) (Fig. 2a). Regarding UH-RA.21,

Table 2 Percentage of patients and controls positive for IgG, IgM, and IgA isotypes within antibodies against UH-RA.1 and UH-RA.21

\begin{tabular}{|c|c|c|c|c|c|c|c|c|}
\hline \multirow[b]{2}{*}{ Number of different isotypes present } & \multicolumn{4}{|c|}{ Anti-UH-RA.1 antibodies } & \multicolumn{4}{|c|}{ Anti-UH-RA.21 antibodies } \\
\hline & Total $(n=463)$ & $\mathrm{RA}(n=285)$ & $\mathrm{RC}(n=88)$ & $\mathrm{HC}(n=90)$ & Total $(n=463)$ & $\mathrm{RA}(n=285)$ & $\mathrm{RC}(n=88)$ & $\mathrm{HC}(n=90)$ \\
\hline$\overline{0}$ & $333(72)$ & $203(71)$ & $62(70)$ & $68(76)$ & $305(66)$ & $182(64)$ & $55(63)$ & $68(76)$ \\
\hline 1 & $104(22)$ & $66(23)$ & $21(24)$ & $17(19)$ & $116(25)$ & $72(25)$ & $26(30)$ & $18(20)$ \\
\hline 2 & $22(5)$ & $14(5)$ & $3(3)$ & $5(6)$ & $36(8)$ & $27(9)$ & $6(7)$ & $3(3)$ \\
\hline 3 & $4(1)$ & $2(1)$ & $2(2)$ & $0(0)$ & $6(1)$ & $4(1)$ & $1(1)$ & $1(1)$ \\
\hline
\end{tabular}

$H C$ healthy control subjects, $R A$ patients with rheumatoid arthritis, $R C$ rheumatic control subjects

The presence of anti-UH-RA.1 and -UH-RA.21 antibodies of the IgG, IgM, and IgA isotype was determined in 285 patients with RA, 88 RC, and 90 HC. Data are presented as absolute number (percent). Contingency analyses for individual isotypes or the number of isotypes did not show any significant differences between the three study populations 

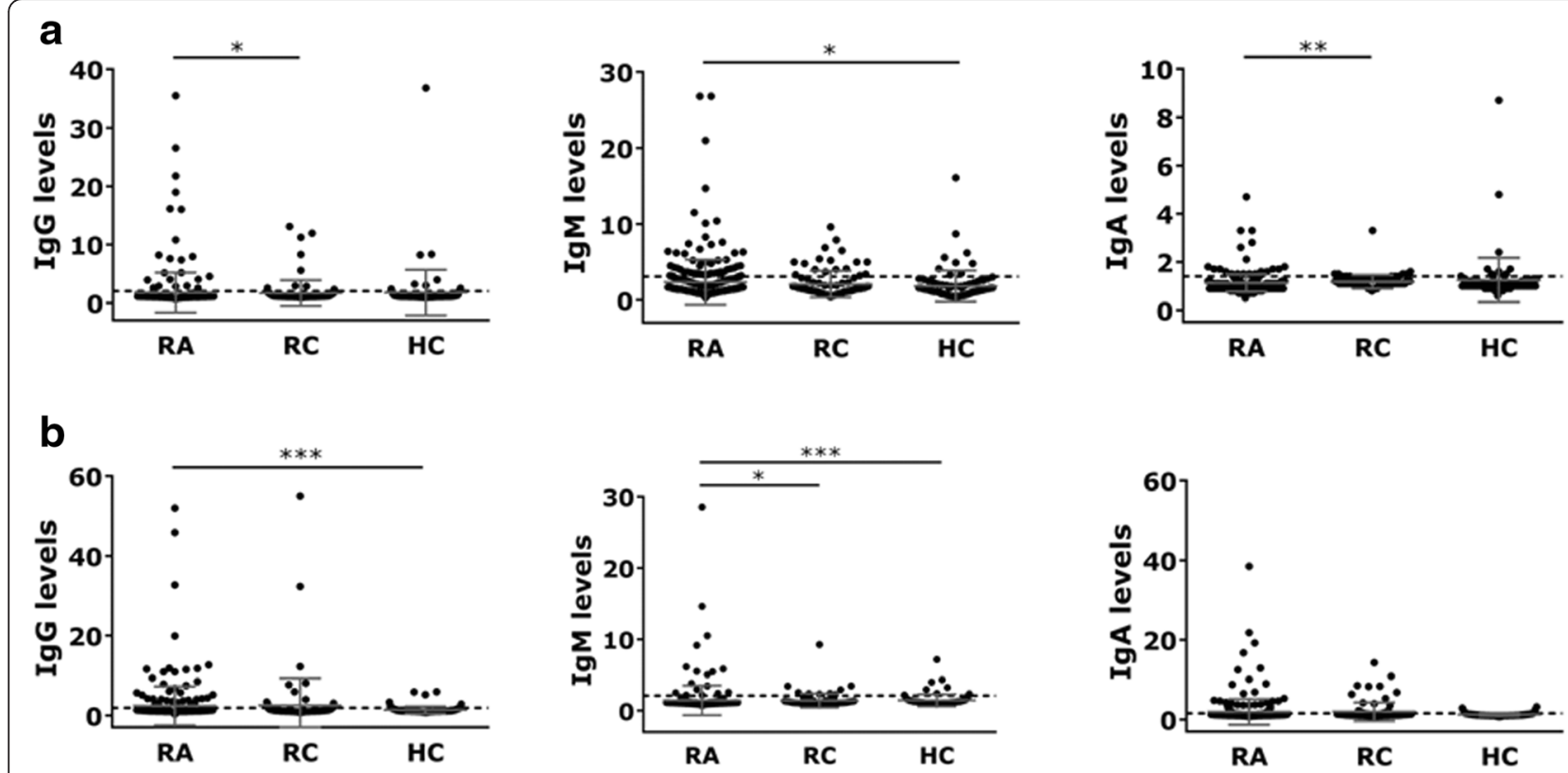

Fig. 2 Levels of anti-UH-RA.1 (a) and anti-UH-RA.21 (b) antibody isotypes in patients with rheumatoid arthritis and control subjects. The dashed lines represent the cutoff value, set at $90 \%$ based on reactivity in healthy controls. Antibody levels were compared by Kruskal-Wallis testing. ${ }^{*} p<$ $0.05,{ }^{* *} p<0.01,{ }^{* * *} p<0.001$. HC healthy control subjects, $\lg$ immunoglobulin, RA patients with rheumatoid arthritis, $R C$ rheumatic control subjects

patients with RA showed significantly higher levels of IgG and IgM compared with HC. IgM levels were also significantly higher in patients with RA than in RC (Fig. 2b).

Cutoff values based on reactivity in $\mathrm{HC}$ and set to $90 \%$ specificity resulted in sensitivity values of $9 \%$ for RA and $8 \%$ for anti-UH-RA.1 IgG and IgA, respectively (Fig. 3a). The highest sensitivity for anti-UH-RA.1 antibody testing was achieved by testing for IgM (18\%). Even combining two or three antibody isotypes did not exceed this sensitivity observed for IgM. IgM together with IgG or IgA resulted in RA sensitivity of $13 \%$ and $16 \%$, respectively. Because of the strong correlation between IgG and IgA, combined testing did not perform better than testing for both isotypes individually. The three antibody isotypes together ended up with a sensitivity of $15 \%$.
Within this study, testing for anti-UH-RA.21 IgG resulted in an RA sensitivity of $23 \%$, which was slightly improved by combined testing with IgM (24\%), IgA (27\%), or both (26\%) (Fig. 3b). Testing for anti-UHRA.21 IgM or IgA yielded individual sensitivities of $6 \%$ and $20 \%$, respectively, or a combined sensitivity of $21 \%$.

\section{Isotype-specific testing in early and seronegative rheumatoid arthritis}

The study population included 285 patients with RA, of whom 105 were $\mathrm{RF}-/ \mathrm{ACPA}-, 19$ were $\mathrm{RF}-/ \mathrm{ACPA}+, 43$ were $\mathrm{RF}+/ \mathrm{ACPA}-$, and 118 were $\mathrm{RF}+/ \mathrm{ACPA}+$. Within all serological subgroups, the full isotype use was found for antibodies against UH-RA.1 and UH-RA.21. Levels of anti-UH-RA.1 IgG, IgM, or IgA were not different between these serological subgroups. The sensitivities of
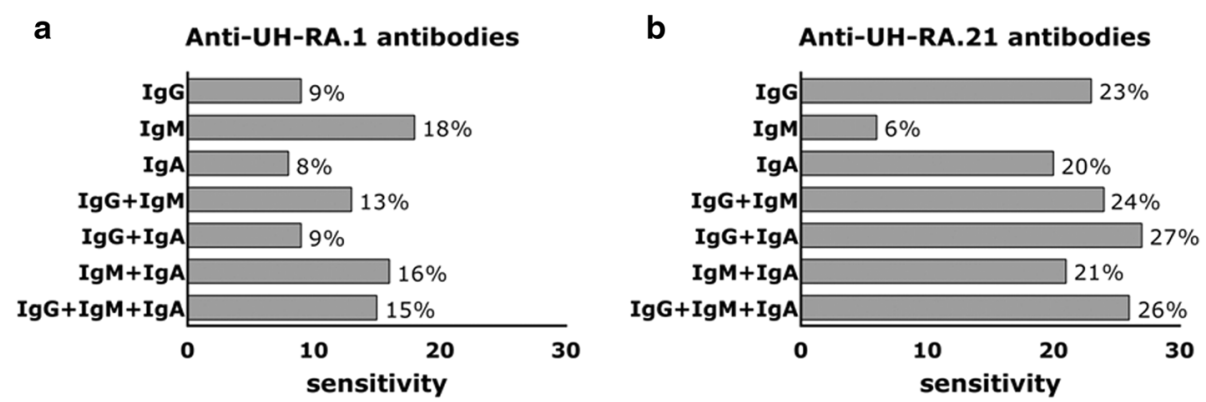

Fig. 3 Sensitivity of isotype-specific testing for antibodies against UH-RA.1 (a) and UH-RA.21 (b) in patients with rheumatoid arthritis (RA), with an associated specificity of $90 \%$. Cutoff values were determined on the basis of reactivity in healthy controls, and specificity was set to $90 \%$. Bars represent the proportion of positive patients, and corresponding sensitivity for RA is provided. Ig immunoglobulin 
the antibody isotypes within seronegative RA were $9 \%$, $20 \%$, and $9 \%$ for IgG, IgM, and IgA, respectively, which were similar to the values for the total RA population. Notably, the reduction of the serological gap by $9 \%$ following testing for IgG reactivity to UH-RA.1 and UHRA.21 (combined as UH-RA.PANEL2), as reported recently (Fig. 4a) [12], was markedly improved to a reduction by $13 \%$ after including anti-UH-RA.1 IgM testing in the panel (Fig. 4b).

For antibodies against UH-RA.21, no differences were observed in antibody levels between serological subgroups or sensitivities of individual isotype testing. The sensitivities of anti-UH-RA.21 IgG, IgM, or IgA in seronegative patients with RA were $24 \%, 8 \%$, and $17 \%$, respectively.

Another diagnostically challenging subpopulation of patients with RA is patients in the early stage of the disease. This study population contained 36 patients with RA who were diagnosed not more than 1 year before sampling and therefore were classified as having early RA. While all antibody isotypes were found in early stages of the disease for both antibody systems (UHRA.1 and UH-RA.21), the levels of IgG, IgM, and IgA isotypes were similar between the early and established RA subgroups.

\section{Prognostic information based on antibody (sub)class testing}

Possible associations between antibody isotypes and clinical data were investigated to explore prognostic information based on isotype distribution. Within this study, a link was found between smoking and the presence of anti-UH-RA.1 antibodies of the IgA class: IgA was found in 4 of 16 smokers and 0 of 77 nonsmokers ( $p=0.001$ by Fisher's exact test). No other prognostic information could be deduced from isotype-specific testing for antiUH-RA.1 antibodies. Regarding antibodies against UHRA.21, an association was found between the presence of erosions and levels of IgG ( $p=0.028$ by MWU) or IgG2 ( $p=0.033$ by MWU). For both (sub)classes, associations were observed for ESR (IgG: $p=0.010$ by MWU and $p=0.045$ by $x^{2}$; IgG2: $p<0.0001$ by $x^{2}$ ). Additionally, ESR was associated with a positive test result for antiUH-RA.21 IgM $\left(p=0.004\right.$ by $\left.\chi^{2}\right)$. Finally, ESR levels were also higher when a higher number of different anti-UHRA.21 antibody isotypes were present, as shown in Fig. 5 $\left(X^{2}=13.20, p=0.004\right)$.

\section{Discussion}

In this study, we report the contribution of individual Ig classes of the IgG, IgM, and IgA types to total reactivity of novel autoantibodies against UH-RA.1 and UHRA.21. Both antibody systems were represented by the full isotype repertoire, and the isotype profile was similar in patients with RA and RC. The major difference in isotype distribution between the two antibody systems was the contribution of IgM. For antibodies against UHRA.1, IgM accounted for half of the reactivity, whereas for anti-UH-RA.21 antibodies the other two isotypes were twice as prevalent. IgM is the first antibody produced during the primary humoral immune response [14]. The presence of IgM is therefore associated with recent antigen exposure. If the antigenic stimulus persists, the $\mu$ chain is changed to $\gamma$ (IgG) or $\alpha$ (IgA) [15]. The presence of the latter isotypes thus points toward a secondary antibody response. Because the presence of
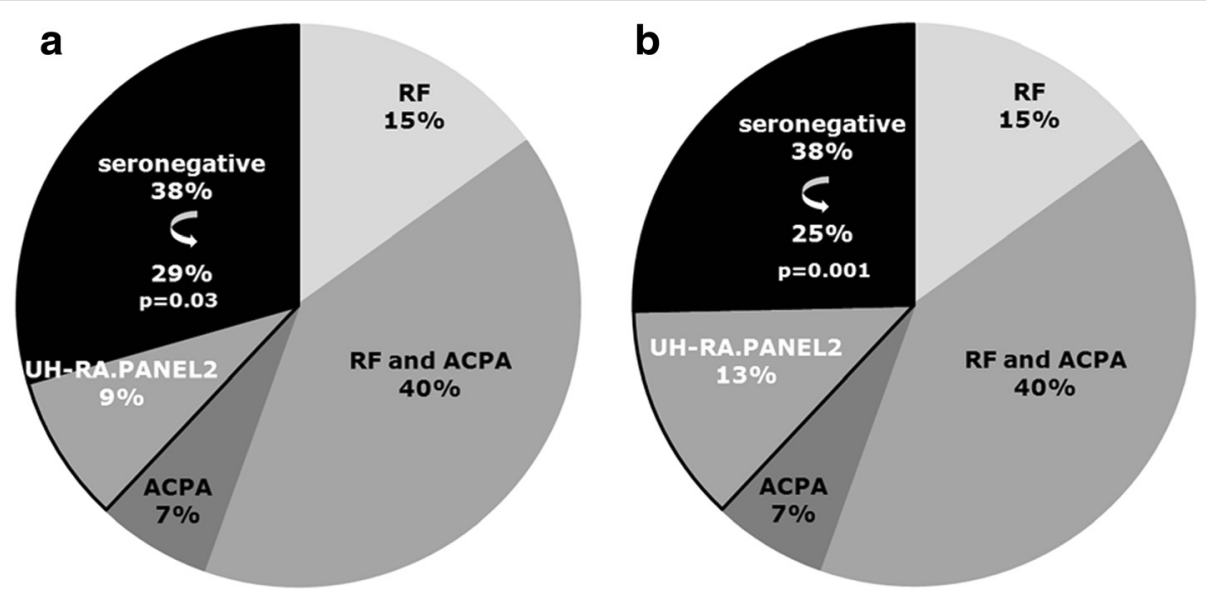

Fig. 4 Improved diagnosis of seronegative patients with rheumatoid arthritis (RA) when testing for anti-UH-RA.1 immunoglobulin (Ig) M was added to the original IgG-specific testing for autoantibodies against UH-RA.1 and UH-RA.21. a Testing for novel autoantibodies against UH-RA.1 and UH-RA.21 (combined as UH-RA.PANEL2) was previously shown to reduce the serological gap by $9 \%$, based on lgG-specific testing. $\mathbf{b}$ Inclusion of antibodies against UH-RA.1 of the IgM isotype increases the sensitivity of the novel autoantibodies in patients with seronegative RA, improving the reduction of the serological gap from $9 \%$ to $13 \%$. ACPA anticitrullinated protein antibodies, RF rheumatoid factor 


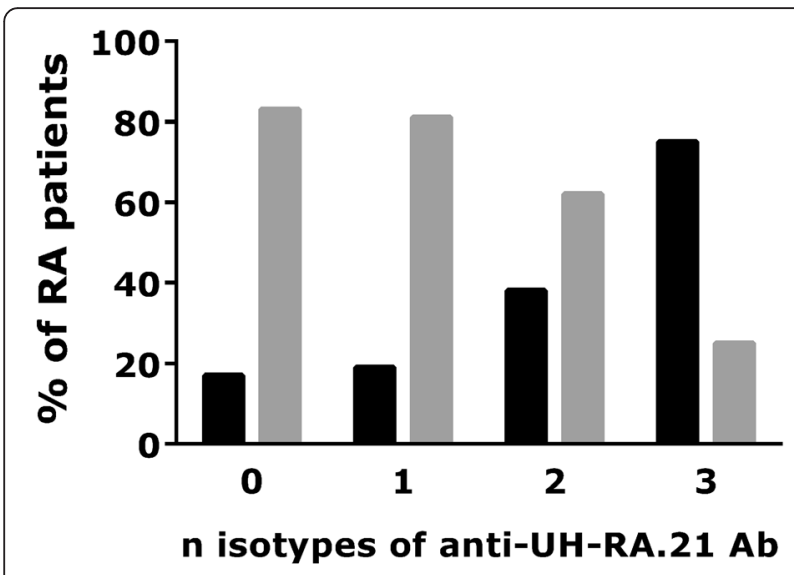

\% elevated ESR

$\%$ normal ESR

Fig. 5 Percentage of patients with rheumatoid arthritis (RA) with normal and elevated erythrocyte sedimentation rate (ESR) in relation to the number of anti-UH-RA.21 antibody isotypes present (among immunoglobulin [lg] G, M, and A). The presence of anti-UH-RA.21 antibodies of the IgG, IgM, and IgA isotypes was determined in 269 samples of patients with RA with data on ESR provided. An elevation of ESR was defined as $>20 \mathrm{~mm} / \mathrm{h}$ for men and $>30 \mathrm{~mm} / \mathrm{h}$

for women

IgG is typical of a persistent immune response and because of its relative abundance, IgG is often the first choice in diagnostic testing for chronic conditions. However, as the presence of IgM is indicative of recent antigen exposure, we can presume that the antibody response against UH-RA.1 (and, to a lesser extent, UHRA.21) is marked by an ongoing immune response and a continuous (re)activation of the immune system. How IgM production is sustained in the presence of IgG against the same antigen is not fully understood, but similar observations have been reported for ACPA [16]. $\operatorname{Ig} \mathrm{A}$, then, is the key component of the humoral response in mucosal tissue such as the lungs or the gut [17]. Its presence in the mucosa of the lungs to protect the epithelial surface might explain the higher participation of anti-UH-RA.1 IgA in smokers than in nonsmokers as has also been observed for RF and ACPA. Patients with pre-RA who were smokers were significantly more often IgA RF-positive [18]. Furthermore, IgA ACPA appeared earlier in smokers than in nonsmokers [5, 7, 8].

Regarding the IgG subclasses, the majority of antiUH-RA.1 antibody reactivity was attributable to IgG3, the most proinflammatory and pathogenic subclass because it is a potent activator of the complement cascade $[19,20]$. This role is shared with IgG1, also found within the anti-UH-RA.1 antibody response. The dominance of the IgG3 subclass in the anti-UH-RA.1 antibody system seems not in line with previous findings of an association between the presence of the antibodies and the achievement of sustained DMARD-free remission [12]. However, IgG antibodies can act in anti-inflammatory ways as well through the engagement of type II Fc receptors (FcRII) rather than FcRI [21]. This is mediated by the glycan core structure of IgG, and modifications such as galactosylation and sialylation have been shown to shift the activity from pro- to anti-inflammatory [22-26]. Sialylated IgG-Fc, for instance, upregulates the inhibitory receptor FcyRIIB, increasing the activation threshold of innate effector cells to immune complexes [27].

For IgG subclasses directed against UH-RA.21, IgG2 was the most abundant subclass, followed by IgG3 and IgG1. IgG2 is considered less pathogenic than IgG3 and IgG1, and so far the IgG2 isotype is less comprehensively understood. Further characterization of the biological properties (e.g., glycan modifications) of the anti-UHRA.1 and anti-UH-RA.21 antibody isotypes will clarify the significance of the isotypes in the pathophysiology of RA.

The use of multiple antibody isotypes raised the question whether isotype-specific testing could add value to the diagnostic performance of the antibodies. Up to now, antibody reactivity against UH-RA.1 and UHRA.21 has been measured using an anti-IgG detection antibody. In the present study, isotype-specific testing for anti-UH-RA.1 antibodies suggested an improvement by testing for IgM rather than IgG, as the sensitivity in patients with RA was twice as high (18\% versus $9 \%$ ) when RA specificity was set to $90 \%$. Also, the levels of anti-UH-RA.1 IgM were significantly higher in patients with RA than in $\mathrm{RC}$ or $\mathrm{HC}$. Although IgG1 and IgG2 were RA-specific compared with $\mathrm{RC}$ and $\mathrm{HC}$, their prevalence was too low to consider them for isotypespecific diagnostic testing. For anti-UH-RA.21 antibody testing, the sensitivity was shown to increase when IgA was added to the current IgG detection. Importantly, the full antibody isotype use was already present in early stages of the disease. Furthermore, the full antibody isotype use was detected in seronegative patients with RA. These findings further support the promising role of the antibody systems in the diagnosis of patients with early and seronegative RA.

\section{Conclusions}

We examined the isotype distribution of antibodies against UH-RA.1 and UH-RA.21. Since effector functions differ between antibody classes and subclasses, the study of the isotype profile is important to understanding the pathophysiological role of the antibody systems. At present, we can only speculate about the exact mechanisms by which anti-UH-RA.1 and anti-UH-RA.21 antibodies work, but we have outlined the isotype profile for 
both antibodies. The exact mechanisms by which the isotypes act need further investigation. The main finding of this work is that full antibody isotype use in early and seronegative RA was demonstrated. The impact of the full use of the antibody isotype repertoire was evaluated for diagnostic application, and, interestingly, the sensitivity of anti-UH-RA.1 antibodies was shown to increase considerably when we measured IgM instead of IgG.

\section{Abbreviations}

ACPA, anticitrullinated protein antibodies; CCP, cyclic citrullinated peptide; DMARD, disease-modifying antirheumatic drug; ESR, erythrocyte sedimentation rate; FCR, FC receptor; HC, healthy control subjects; Ig, immunoglobulin; MWU, Mann-Whitney $U$ test; NA, not applicable or not available; OD, optical density; $\mathrm{RA}$, rheumatoid arthritis; RC, rheumatic control subjects; RF, rheumatoid factor; UH, Hasselt University; ULN, upper limit of normal

\section{Acknowledgements}

This work could not have been accomplished without the generous contributions of the participating patients and the rheumatologists from ReumaClinic Genk, Dr. H. Berghs, Dr. M. Coppens, Dr. A. Sileghem and Dr. P. Volders, the other rheumatologists from Reuma Instituut Hasselt, Dr. L. Corluy, Dr. C. Langenaken and Dr. P. Van Wanghe, and their assisting personnel. Dr. C. Langenaken also provided samples from the Centrum Voor Huisartsen at Tessenderlo, Belgium. The authors thank Dr. B. Van Woensel for her efforts in incorporating healthy controls and I. Rutten and K. Ulenaers for excellent technical assistance. INOVA Diagnostics Inc. is thanked for providing QUANTA Lite CCP3 assays.

\section{Funding}

This work was supported by Research Foundation Flanders (FWOVlaanderen), the University of Hasselt and the transnational University Limburg. We thank Pfizer for providing support of the database formation for clinical data, and also for blood sample collection.

\section{Authors' contributions}

LMDW performed the experiments and data analysis, and drafted the manuscript. PG recruited patients, provided samples, helped in revising the manuscript and participated in the study design and conception. JL recruited patients, provided samples and revised the manuscript. JV recruited patients, provided samples and revised the manuscript. PS helped in revising the manuscript and participated in study design and conception. VS was responsible for study design and conception, and assisted in interpreting the results of the study and in the writing of the manuscript. All authors read and approved the final manuscript.

\section{Competing interests}

PG provides lectures, consulting advice and collaboration in clinical studies with Amgen, Roche, GlaxoSmithKline, Novartis, Merck Sharp \& Dohme, Pfizer, Procter \& Gamble, Eli Lilly, Abbott Laboratories, Will, Sanofi-Aventis, AbbVie, UCB, Menarini and Bristol-Myers Squibb. JL has received consultancy and study fees from Pfizer, AbbVie, Novartis, Bristol-Myers Squibb, Janssen-Cilag and Merck Sharp \& Dohme. The authors declare that they have no competing interests.

\section{Author details}

${ }^{1}$ Biomedical Research Institute, Hasselt University, and School of Life Sciences, transnational University Limburg, Martelarenlaan 42, 3500 Hasselt, Belgium. ${ }^{2}$ ReumaClinic, Genk, Belgium. ${ }^{3}$ Rheumatology, Maastricht University Medical Center, Maastricht, The Netherlands. ${ }^{4}$ Reuma Instituut, Hasselt, Belgium. ${ }^{5}$ Jessa Hospitals, Hasselt, Belgium.

Received: 10 November 2015 Accepted: 20 May 2016 Published online: 07 June 2016

\section{References}

1. Rantapää-Dahlqvist S, de Jong BA, Berglin E, Hallmans G, Wadell G, Stenlund $\mathrm{H}$, et al. Antibodies against cyclic citrullinated peptide and IgA rheumatoid factor predict the development of rheumatoid arthritis. Arthritis Rheum. 2003;48(10):2741-9.
2. Berglin $E$, Johansson $T$, Sundin $U$, Jidell $E$, Wadell $G$, Hallmans $G$, et al. Radiological outcome in rheumatoid arthritis is predicted by presence of antibodies against cyclic citrullinated peptide before and at disease onset, and by IgA-RF at disease onset. Ann Rheum Dis. 2006:65(4):453-8.

3. Aletaha D, Neogi T, Silman AJ, Funovits J, Felson DT, Bingham 3rd CO, et al. 2010 Rheumatoid arthritis classification criteria: an American College of Rheumatology/European League Against Rheumatism collaborative initiative. Ann Rheum Dis. 2010;69(9):1580-8.

4. Verpoort KN, Jol-van der Zijde CM, Papendrecht-van der Voort EA, loan-Facsinay A, Drijfhout JW, van Tol MJ, et al. Isotype distribution of anti-cyclic citrullinated peptide antibodies in undifferentiated arthritis and rheumatoid arthritis reflects an ongoing immune response. Arthritis Rheum. 2006;54(12):3799-808.

5. Ioan-Facsinay A, Willemze A, Robinson DB, Peschken CA, Markland J, van der Woude D, et al. Marked differences in fine specificity and isotype usage of the anti-citrullinated protein antibody in health and disease. Arthritis Rheum. 2008;58(10):3000-8.

6. Lakos G, Soos L, Fekete A, Szabo Z, Zeher M, Horvath IF, et al. Anti-cyclic citrullinated peptide antibody isotypes in rheumatoid arthritis: association with disease duration, rheumatoid factor production and the presence of shared epitope. Clin Exp Rheumatol. 2008;26(2):253-60.

7. Svärd A, Kastbom A, Reckner-Olsson A, Skogh T. Presence and utility of IgAclass antibodies to cyclic citrullinated peptides in early rheumatoid arthritis: the Swedish TIRA project. Arthritis Res Ther. 2008;10(4):R75.

8. Kokkonen H, Mullazehi M, Berglin E, Hallmans G, Wadell G, Ronnelid J, et al. Antibodies of IgG, IgA and IgM isotypes against cyclic citrullinated peptide precede the development of rheumatoid arthritis. Arthritis Res Ther. 2011; 13(1):R13

9. van der Woude D, Rantapää-Dahlqvist S, loan-Facsinay A, Onnekink C, Schwarte CM, Verpoort KN, et al. Epitope spreading of the anti-citrullinated protein antibody response occurs before disease onset and is associated with the disease course of early arthritis. Ann Rheum Dis. 2010;69(8):1554-61.

10. van der Woude D, Syversen SW, van der Voort El, Verpoort KN, Goll GL, van der Linden MP, et al. The ACPA isotype profile reflects long-term radiographic progression in rheumatoid arthritis. Ann Rheum Dis. 2010;69(6):1110-6.

11. Somers K, Geusens P, Elewaut D, De Keyser F, Rummens JL, Coenen M, et al Novel autoantibody markers for early and seronegative rheumatoid arthritis. J Autoimmun. 2011;36(1):33-46.

12. De Winter LM, Hansen WL, van Steenbergen HW, Geusens $P$, Lenaerts J, Somers K, et al. Autoantibodies to two novel peptides in seronegative and early rheumatoid arthritis. Rheumatology (Oxford). doi:10.1093/ rheumatology/kew198.

13. Arnett FC, Edworthy SM, Bloch DA, McShane DJ, Fries JF, Cooper NS, et al. The American Rheumatism Association 1987 revised criteria for the classification of rheumatoid arthritis. Arthritis Rheum. 1988;31(3):315-24.

14. Boes $M$. Role of natural and immune $\lg M$ antibodies in immune responses. Mol Immunol. 2000;37(18):1141-9.

15. Manis JP, Tian M, Alt FW. Mechanism and control of class-switch recombination. Trends Immunol. 2002;23(1):31-9.

16. Suwannalai $P$, Willemze A, van Toorn L, Stoeken-Rijsbergen G, Levarht $N$, Drijfhout JW, et al. The fine specificity of IgM anti-citrullinated protein antibodies (ACPA) is different from that of IgG ACPA. Arthritis Res Ther. 2011;13(6):R195

17. Fagarasan S, Honjo T. Regulation of IgA synthesis at mucosal surfaces. Curr Opin Immunol. 2004;16(3):277-83.

18. Masdottir B, Jonsson T, Manfredsdottir V, Vikingsson A, Brekkan A, Valdimarsson H. Smoking, rheumatoid factor isotypes and severity of rheumatoid arthritis. Rheumatology. 2000;39(11):1202-5.

19. Dijstelbloem HM, van de Winkel JG, Kallenberg CG. Inflammation in autoimmunity: receptors for lgG revisited. Trends Immunol. 2001;22(9):510-6.

20. Nimmerjahn F. Activating and inhibitory FcyRs in autoimmune disorders. Springer Semin Immunopathol. 2006;28(4):305-19.

21. Pincetic A, Bournazos S, DiLillo DJ, Maamary J, Wang TT, Dahan R, et al. Type I and type II Fc receptors regulate innate and adaptive immunity. Nat Immunol. 2014;15(8):707-16.

22. Bondt A, Selman MH, Deelder AM, Hazes JM, Willemsen SP, Wuhrer M, et al. Association between galactosylation of immunoglobulin $\mathrm{G}$ and improvement of rheumatoid arthritis during pregnancy is independent of sialylation. J Proteome Res. 2013;12(10):4522-31.

23. Sondermann P, Pincetic A, Maamary J, Lammens K, Ravetch JV. General mechanism for modulating immunoglobulin effector function. Proc Natl Acad Sci U S A. 2013;110(24):9868-72. 
24. Kaneko Y, Nimmerjahn F, Ravetch JV. Anti-inflammatory activity of immunoglobulin G resulting from Fc sialylation. Science. 2006:313(5787):670-3.

25. Anthony RM, Wermeling F, Ravetch JV. Novel roles for the IgG Fc glycan. Ann N Y Acad Sci. 2012:1253:170-80.

26. Ahmed AA, Giddens J, Pincetic A, Lomino JV, Ravetch JV, Wang LX, et al. Structural characterization of anti-inflammatory immunoglobulin G Fc proteins. J Mol Biol. 2014;426(18):3166-79.

27. Fiebiger BM, Maamary J, Pincetic A, Ravetch JV. Protection in antibody- and T cell-mediated autoimmune diseases by antiinflammatory lgG Fcs requires type II FcRs. Proc Natl Acad Sci U S A. 2015;112(18):E2385-94.

Submit your next manuscript to BioMed Central and we will help you at every step:

- We accept pre-submission inquiries

- Our selector tool helps you to find the most relevant journal

- We provide round the clock customer support

- Convenient online submission

- Thorough peer review

- Inclusion in PubMed and all major indexing services

- Maximum visibility for your research

Submit your manuscript at www.biomedcentral.com/submit 